\title{
TRANSFUSIÓN DE PLASMA CONVALECIENTE DE PACIENTES CON COVID-19
}

\author{
César A. Galván (101,2,a,b, Crhistian Toribio-Dionicio (10,3,a, Marco Álvarez-Ángeles (102,4,c,

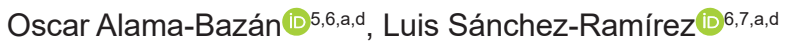 \\ 1 Unidad Funcional de Alergia, Asma e Inmunología (UFAAI) del Instituto Nacional de Salud del Niño (INSN), Lima, Perú. \\ 2 Sociedad Peruana de Inmunología (SPI), Lima, Perú. \\ 3 Facultad de Medicina, Universidad Nacional Mayor de San Marcos (UNMSM), Lima, Perú. \\ ${ }^{4}$ Instituto de Hemaféresis y Terapia Celular (IHEMATEC), Lima, Perú. \\ 5 Servicio de Bioquímica e Inmunoquímica del Hospital Nacional Alberto Sabogal Sologuren (HNASS), Lima, Perú. \\ ${ }^{6}$ Asociación Médica Peruana de Patología Clínica (AMPPC), Lima, Perú. \\ 7 Banco de Sangre del Instituto Nacional de Enfermedades Neoplásicas (INEN), Lima, Perú. \\ a Médico cirujano; ${ }^{\mathrm{b}}$ especialista en Inmunología y Alergología; ${ }^{\mathrm{c}}$ tecnólogo médico, magíster en Ciencias; ${ }^{\mathrm{d}}$ especialista en \\ Patología Clínica.
}

\section{RESUMEN}

Actualmente no existe vacuna disponible ni medicación específica contra la enfermedad por coronavirus 2019 (COVID-19). El tratamiento se basa fundamentalmente en medidas de soporte. En este contexto, se han aprobado múltiples terapias de potencial utilidad para su uso en ensayos clínicos, como la transfusión de plasma convaleciente (TPC). Se realizó una búsqueda en PubMed de estudios sobre plasma convaleciente y COVID-19, SARS o MERS. Los estudios sobre la eficacia clínica en enfermedades causadas por otros coronavirus (SARSCoV y MERS-CoV) evidenciaron mejoría clínica, aumento de anticuerpos neutralizantes, disminución de la mortalidad y ausencia de eventos adversos durante y después del tratamiento. En el caso de la COVID-19, se encontraron 13 estudios en pacientes con la COVID-19 grave y crítica. Aunque existen limitaciones en la metodología, en el número de pacientes y en los protocolos para el análisis del plasma convaleciente de los donantes, los pacientes que recibieron TPC evidenciaron mejoría clínica, mejoría de patrones ventilatorios, resolución de lesiones pulmonares, disminución de mortalidad, mejoría de parámetros laboratoriales, aumento de anticuerpos neutralizantes, disminución de carga viral y baja frecuencia de eventos adversos.

Palabras clave: COVID-19; Plasma; Virus MERS; Virus SARS (Fuente: DeCS BIREME).

\section{TRANSFUSION OF CONVALESCENT PLASMA FROM PATIENTS WITH COVID-19}

\begin{abstract}
There is currently no vaccine available and no specific medication against Coronavirus 2019 disease (COVID-19). The treatment is mainly based on support measures. In this context, several potentially useful therapies have been approved for use in clinical trials, such as convalescent plasma transfusion (CPT). PubMed was searched for studies on convalescent plasma and COVID-19, SARS or MERS. Studies on clinical efficacy in diseases caused by other coronaviruses (SARS-CoV and MERS-CoV) showed clinical improvement, increase of neutralizing antibodies, decreased mortality and absence of adverse events during and after treatment. We found 13 studies on this type of treatment used in patients with severe and critical COVID-19. Despite limitations regarding methodology, number of patients and the protocols for the analysis of donors' convalescent plasma, patients who received CPT showed clinical improvement, improvement of ventilatory patterns, resolution of lung injuries, decreased mortality, improvement of laboratory parameters, increase of neutralizing antibodies, decreased viral load and low frequency of adverse events.
\end{abstract}

Dionicio C, Álvarez-Ángeles M, Alama-Bazán O, Sánchez-Ramírez L. Transfusión de plasma convaleciente de pacientes con COVID-19. Rev Peru Med Exp Salud Publica. 2020;37(4):746-54. doi: https://doi. org/10.17843/rpmesp.2020.374.5767.

Correspondencia: Crhistian ToribioDionicio; crhistiantoribiodionicio@ gmail.com

Keywords: COVID-19; Plasma; MERS Virus; SARS Virus (source: MeSH NLM).

\section{INTRODUCCIÓN}

Al 10 de agosto del 2020, la pandemia de la enfermedad por coronavirus 2019 (COVID-19) ha producido 728013 muertes y 19718030 infectados en más de 200 países ${ }^{(1)}$. En el Perú, los contagios siguen en aumento; al 8 de agosto, se reportó un total de 483133 casos y un total de 21276 fallecidos, lo que equivale a una letalidad del $4,4 \%{ }^{(2)}$. Actualmente, no existe vacuna disponible ni medicación específica contra la COVID-19 y el tratamiento se basa fundamentalmente en 
medidas de soporte. En este contexto, se han aprobado múltiples terapias de potencial utilidad para su uso en ensayos clínicos, como la transfusión de plasma convaleciente (TPC).

La TPC consiste en la administración pasiva de anticuerpos policlonales, lo que genera una respuesta inmune inmediata con el objetivo de tratar una enfermedad infecciosa o prevenir la infección en un individuo susceptible ${ }^{(3)}$. El uso de plasma como tratamiento de enfermedades infecciosas se remonta a 1890, con los experimentos de Behring y Kitasato quienes usaron el suero de animales previamente infectados e inmunes contra la difteria y el tétanos en otros animales ${ }^{(4)}$. Uno de los primeros estudios que evaluó el efecto de la transfusión de plasma de humanos se realizó en pacientes con fiebre amarilla en Cuba ${ }^{(5)}$. Posteriormente, durante la pandemia de la gripe española en 1918 ocasionada por el virus de la gripe $\mathrm{A}(\mathrm{AH} 1 \mathrm{~N} 1)$ de origen porcino, se usó el plasma para el tratamiento de pacientes con neumonía y se observó una mejoría clínica y la reducción de la mortalidad ${ }^{(6)}$, así como en el tratamiento de múltiples enfermedades infecciosas como el ántrax, la peste, la fiebre escarlatina, el sarampión, la tularemia, la difteria, la meningitis meningocócica o la rabia que, si bien con la aparición de la terapia antibiótica disminuyó su uso, se mantiene como opción terapéutica frente a infecciones virales emergentes (7-11), como en el brote del Ébola en 2014 donde se recomendó su uso como tratamiento empírico ${ }^{(12)}$. Asimismo, el plasma también se usó durante la pandemia de gripe de 2009 y en otras infecciones por coronavirus, como la del síndrome respiratorio agudo severo (SARS-CoV) en 2003 y el síndrome respiratorio de Oriente Medio (MERS-CoV) en $2012^{(13)}$.

Los probables mecanismos de acción de este tipo de terapia son la neutralización viral (mediada por anticuerpos IgG o IgM) y la inmunomodulación (mediada por la interacción entre anticuerpos y células o proteínas del complemento), como la neutralización de autoanticuerpos, la inhibición de la formación de inmunocomplejos, la neutralización de citoquinas proinflamatorias como IL- $1 \beta$ y TNF- $\alpha$, la citotoxicidad celular mediada por anticuerpos, la opsonización, la activación de complemento, la fagocitosis, la proliferación de linfocitos $\mathrm{T}$ reguladores, la disminución de linfocitos $\mathrm{T}$ helper 1 (Th1), el aumento de linfocitos Th2 y la disminución de la expresión de moléculas coestimuladoras en la presentación antigénica ${ }^{(14,15)}$. El resultado de estos mecanismos es el aumento o la disminución de la respuesta inflamatoria que dependerá del tipo de interacción entre anticuerpos y receptores presentes en células específicas ${ }^{(14,16)}$. Aunque esta terapia puede usarse tanto en la prevención como en el tratamiento de una determinada infección, existe evidencia que sugiere una mejor eficacia si se usa en la prevención, posiblemente, debido a la cantidad de inóculo inicial y su neutralización, la cual es menor si el individuo no está infectado ${ }^{(17)}$, o a la modificación de la respuesta inflamatoria, mediada por anticuerpos, en estadios donde la respuesta inmune es inicial y el individuo es asintomático ${ }^{(14)}$.
La aféresis es el método recomendado para la obtención de plasma debido a la gran cantidad de volumen recolectado (400 a $800 \mathrm{~mL}$ ) en una donación simple, a la posibilidad de realizar donaciones frecuentes y a los pocos efectos en el nivel de hemoglobina del donante (debido a la posibilidad de la reinfusión de glóbulos rojos) ${ }^{(3,18)}$. En zonas donde hay una epidemia, la recolección de plasma tiene el valor agregado de proporcionar inmunidad pasiva específica contra el agente infeccioso local, ya que la obtención del plasma en otras zonas podría ser menos efectiva debido a la posible variación del agente infeccioso ${ }^{(19)}$.

Presentamos una revisión de los estudios sobre transfusión de plasma convaleciente para el tratamiento de pacientes con infecciones por coronavirus (SARS, MERS y COVID-19), así como la seguridad de su uso.

\section{BÚSQUEDA Y SELECCIÓN DE EVIDENCIA}

Se realizó una búsqueda bibliográfica de artículos publicados desde el 2003 hasta el 1 de agosto del presente año en PubMed. Se usaron los siguientes términos: "convalescent plasma” AND “COVID-19”/“COVID19”/“SARS-CoV-2"/“MERS"/“SARS". Se incluyeron comentarios, comunicaciones breves, trabajos originales, trabajos cortos y revisiones sistemáticas que se publicaron en español o inglés. De los 106 artículos encontrados, se excluyeron 53 por no estar relacionados con el tema, 15 por no estar en español ni inglés, 18 por ser artículos en preimpresión, 1 por estar duplicado y 1 haber sido corregido (Figura 1). Se analizaron 18 artículos que evaluaron la eficacia de la TPC.

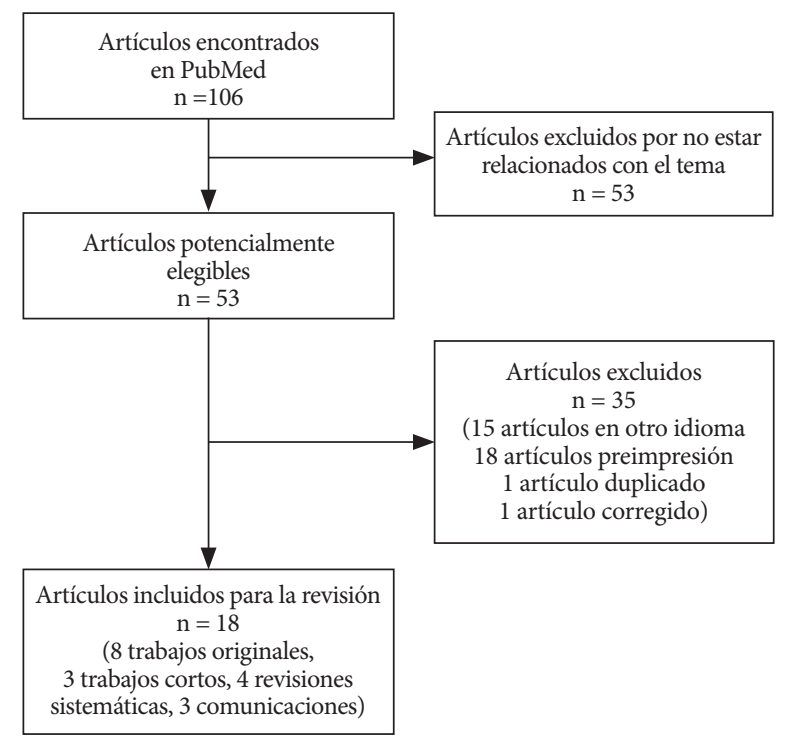

Figura 1. Diagrama de flujo del proceso de búsqueda y selección de artículos. 


\section{TRANSFUSIÓN DE PLASMA CONVALECIENTE DE PACIENTES CON OTRAS INFECCIONES POR CORONAVIRUS}

Diversos estudios evaluaron el uso de la TPC en SARS y MERS (Tabla 1). El estudio más grande analizó retrospectivamente la TPC en 80 pacientes con SARS hospitalizados en Hong Kong ${ }^{(20)}$. El plasma convaleciente (PC) se obtuvo de pacientes recuperados de SARS, es decir, pacientes afebriles por al menos siete días, con mejoría radiológica, sin necesidad de oxígeno suplementario, que habían acudido al centro de salud 14 días después del inicio de los síntomas. Se estableció como un buen resultado, el alta del paciente antes del día 22 del inicio de los síntomas, mientras que un mal resultado, como muerte antes del día 22 o permanencia en hospitalización después del día 22 del inicio de los síntomas. La TPC antes del día 14 del inicio de los síntomas (48 pacientes) evidenció un mejor resultado (58,3\% vs. $15,6 \%)$ y una menor mortalidad (6,3\% vs. $21,9 \%$ ) en comparación con aquellos que se transfundieron después del día 14 del inicio de los síntomas.

Previamente a este estudio, Soo et al. realizaron un análisis retrospectivo comparativo de pacientes con SARS (tratados previamente con metilprednisolona y ribavirina) que recibieron PC (grupo plasma, 19 pacientes) o pulsos adicionales de metilprednisolona (grupo esteroides, 21 pacientes) ${ }^{(21)}$. El 74\% de los pacientes del grupo plasma recibieron el alta el día 22 del inicio de los síntomas, en comparación con el 19\% del gru- po esteroides. Adicionalmente, se reportaron cinco muertes en el grupo esteroides (23,8\%), ninguna muerte en el grupo plasma y un mayor porcentaje de alta al día 22 en el grupo plasma (73,4\% vs. $19 \%)$.

Un estudio prospectivo realizado en Taiwán analizó la TPC en 3 trabajadores de salud, quienes no presentaron mejoría clínica con tratamiento empírico (ribavirina y metilprednisolona) ${ }^{(22)}$. El PC se obtuvo de pacientes recuperados de infección por SARS-CoV. Se observó una disminución de la carga viral de $495 \times 10^{3}, 76 \times 10^{3}$ o $650 \times 10^{3}$ copias $/ \mathrm{mL}$ a 0 o 1 copia/mL 24 horas después de la TPC. Asimismo, los anticuerpos IgG e IgM antiSARS-CoV aumentaron con el tiempo. Dos pacientes presentaron una función pulmonar y capacidad de difusión normal al alta, y una paciente tuvo un bebé 13 meses después del alta. Tanto la madre como el infante presentaron anticuerpos IgG antiSARS-CoV. Este último estudio sugiere la posibilidad de transmisión pasiva de anticuerpos a infantes después de la TPC.

Mair-Jenkins et al. realizaron una revisión sistemática y metaanálisis de 32 estudios que evaluaron la TPC en pacientes con SARS, gripe española (AH1N1), gripe aviar A (H5N5) y gripe pandémica 2009 A (H1N1) ${ }^{(23)}$. Se identificaron ocho estudios observacionales que reportaron disminución de la mortalidad en pacientes con SARS, sin embargo, solo se incluyeron dos estudios para el metaanálisis. Adicionalmente, se incluyeron dos estudios de influenza pandémica 2009, uno de gripe aviar y tres de gripe española. El metaanálisis evidenció una disminución de la mortalidad con un odds ratio (OR): 0,25; intervalo de confianza (IC) al

Tabla 1. Estudios que evaluaron el uso de plasma convaleciente en pacientes con SARS o MERS.

\begin{tabular}{|c|c|c|c|c|c|c|c|}
\hline Autor-país & $\begin{array}{l}\text { Tipo de } \\
\text { estudio }\end{array}$ & $\begin{array}{l}\text { Número de } \\
\text { pacientes }\end{array}$ & $\begin{array}{l}\text { Título de an- } \\
\text { ticuerpos en } \\
\text { donantes }\end{array}$ & Dosis de PC & Resultados & Carga viral & $\begin{array}{l}\text { Eventos adversos } \\
\text { y complicaciones }\end{array}$ \\
\hline $\begin{array}{l}\text { Cheng et al. } \\
\text { Hong Kong }\end{array}$ & $\begin{array}{l}\text { Estudio } \\
\text { retrospectivo } \\
\text { - SARS }\end{array}$ & 80 & $\begin{array}{l}\text { Títulos entre } 1: 160 \\
\text { a 1:2560 (no se } \\
\text { reportó el método } \\
\text { usado) }\end{array}$ & $\begin{array}{l}200 \text { a } 400 \mathrm{~mL} \\
\text { (no se reportó } \\
\text { número de } \\
\text { dosis) }\end{array}$ & $\begin{array}{l}41 \% \text { salieron de alta al día } \leq 22 \text { del inicio de } \\
\quad \text { síntomas } \\
\text { Mejor resultado en el grupo que recibió plasma } \\
\text { al día } 14 \text { del inicio de síntomas: alta hospitalaria } \\
\text { (58.3\% vs. } 15.6 \%) \text { y mortalidad ( } 6.3 \% \text { vs. } 21.9 \%)\end{array}$ & No se reportó & $\begin{array}{l}\text { No se reportaron } \\
\text { eventos adversos ni } \\
\text { complicaciones. }\end{array}$ \\
\hline $\begin{array}{l}\text { Soo et al. } \\
\text { Hong Kong }\end{array}$ & $\begin{array}{l}\text { Estudio } \\
\text { retrospectivo } \\
\text { - SARS }\end{array}$ & 40 & $\begin{array}{l}\text { Títulos entre 1:160 } \\
\text { a 1:2560 (no se } \\
\text { reportó el método } \\
\text { usado) }\end{array}$ & $\begin{array}{l}200 \text { a } 400 \mathrm{~mL} \\
\text { (no se reportó } \\
\text { número de } \\
\text { dosis) }\end{array}$ & $\begin{array}{l}\text { Grupo plasma (19 pacientes) y grupo esteroides } \\
\text { (21 pacientes) } \\
\text { Grupo plasma vs. grupo esteroides: } 73 \% \text { vs. } 19 \% \\
\text { recibieron el alta el día } 22 \text { del inicio de los sínto- } \\
\text { mas, 0\% vs. } 23.8 \% \text { (mortalidad). }\end{array}$ & No se reportó & $\begin{array}{l}\text { No se reportaron } \\
\text { eventos adversos ni } \\
\text { complicaciones. }\end{array}$ \\
\hline $\begin{array}{l}\text { Yeh et al. } \\
\text { China }\end{array}$ & $\begin{array}{l}\text { Serie de casos } \\
\text { - SARS }\end{array}$ & 3 & $\begin{array}{l}\text { IgG }>1: 640 \text { (in- } \\
\text { munofluorescencia } \\
\text { indirecta) }\end{array}$ & $\begin{array}{l}500 \mathrm{~mL} \text { (no se } \\
\text { reportó dosis) }\end{array}$ & $\begin{array}{c}\text { Mejoría clínica y radiológica en la primera } \\
\text { semana de tratamiento. } \\
\text { Aumento de anticuerpos IgG e IgM. } \\
\text { Función pulmonar normal en } 2 \text { pacientes } \\
\text { después del alta. } \\
\text { Presencia de anticuerpos IgG en infante y madre } \\
\text { postembarazo. }\end{array}$ & $\begin{array}{l}\text { Disminución } \\
\text { e indetectable } \\
\text { a las } 24 \text { horas } \\
\text { del trata- } \\
\text { miento. }\end{array}$ & $\begin{array}{l}\text { No se reportaron } \\
\text { eventos adversos ni } \\
\text { complicaciones. }\end{array}$ \\
\hline $\begin{array}{l}\text { Ko et al. } \\
\text { Corea del Sur }\end{array}$ & $\begin{array}{l}\text { Serie de casos } \\
\text { - MERS }\end{array}$ & 3 & TAN $>1: 80$ & No se reportó. & $\begin{array}{l}\text { Mejoría clínica y de soporte ventilatorio entre las } \\
3 \text { semanas de inicio de tratamiento, aumento de } \\
\text { anticuerpos neutralizantes y ELISA IgG entre los } \\
5 \text { días de inicio de tratamiento. }\end{array}$ & $\begin{array}{l}\text { Disminución } \\
\text { e indetectable } \\
\text { dentro de } 1 \text { a } \\
3 \text { semanas del } \\
\text { tratamiento. }\end{array}$ & $\begin{array}{l}\text { No se reportaron } \\
\text { eventos adversos ni } \\
\text { complicaciones. }\end{array}$ \\
\hline
\end{tabular}

ELISA: Ensayo de inmunoabsorción ligado a enzima; PC: plasma convaleciente; TAN: Título de anticuerpos neutralizantes 
95\%: 0,14-0,45; sin embargo, los estudios incluidos fueron de baja o muy baja calidad, no contaron con grupo control y presentaron un sesgo moderado a alto. No se reportaron efectos adversos después de la TPC.

En el caso del MERS, solo se encontró un estudio, realizado en Corea del Sur, que exploró el efecto de la TPC en tres pacientes con infección grave y sus respuestas serológicas postransfusión ${ }^{(24)}$. Solo dos pacientes presentaron actividad neutralizante después de la TPC, sin embargo, el periodo de hospitalización después de la TPC de los tres pacientes fue prolongado (22 días, 94 días y 38 días; respectivamente).

\section{TRANSFUSIÓN DE PLASMA CONVALECIENTE DE PACIENTES CON COVID-19}

Se encontraron 13 estudios que evaluaron el uso de la TPC en pacientes con COVID-19 (Tabla 2). El primer estudio publicado fue de Shen et al. quienes estudiaron el efecto de la TPC en cinco pacientes con COVID-19 y síndrome de distrés respiratorio agudo (SDRA) en China ${ }^{(25)}$. Se usó plasma de donantes recuperados de infección por SARS-CoV-2 con títulos de anticuerpos >1:1000 (medido por ELISA IgG) y títulos de anticuerpos neutralizantes $>1: 40$. Todos los pacientes estuvieron en ventilación mecánica y recibieron tratamiento con metilprednisolona y antivirales. Se evidenció la disminución de la carga viral y de la escala SOFA (Sequential Organ Failure Assessment), el aumento de la proporción $\mathrm{PaO}_{2} / \mathrm{FiO}_{2}$ (mejoría de la hipoxemia) dentro de los doce días de la TPC; la normalización de la temperatura corporal dentro de los tres primeros días, la mejoría de las lesiones pulmonares a partir del tercer día y el aumento de los títulos de anticuerpos contra el SARS-CoV-2 (IgM e IgG) y anticuerpos neutralizantes en el tiempo. El SDRA se resolvió en cuatro pacientes a los 12 días de la TPC y tres pacientes dejaron de usar ventilador mecánico dos semanas después del tratamiento.

Ye et al. reportaron seis pacientes con la COVID-19 admitidos en el hospital de Wuhan Huoshenshan en China ${ }^{(26)}$. Es importante mencionar que, los pacientes atendidos en este hospital fueron tratados previamente en otros centros, por lo que se encontraban en un estadio final de la enfermedad. Se obtuvo PC de pacientes recuperados de la COVID-19. Los donantes eran pacientes sin fiebre por al menos tres días, con mejoría de los síntomas respiratorios, dos pruebas negativas consecutivas por reacción en cadena de la polimerasa (RCP) y al menos tres semanas después del inicio de los síntomas. De los seis pacientes, cinco presentaron opacidades bilaterales y múltiples en vidrio esmerilado asociado a disnea y uso de oxígeno suplementario. Todos los pacientes que presentaron lesiones pulmonares presentaron mejoría clínica (a las 24 horas) e imagenológica (entre tres días a dos semanas). Adicionalmente, dos pacientes presentaron un aumento de los niveles de anticuerpos después de la TPC y no se observaron efectos adversos.

Duan et al. reportaron una serie de diez casos con la COVID-19 grave ${ }^{(27)}$. Todos los pacientes recibieron tratamiento antiviral y antibacteriano o antifúngico en caso de coinfecciones; y opacidades bilaterales en vidrio esmerilado. Se usó una dosis de PC de pacientes recuperados con títulos de anticuerpos neutralizantes (medido por TNRP) >1:640. Se evaluó la seguridad de la TPC, mejoría clínica y parámetros de laboratorio después de tres días del tratamiento. La TPC se administró alrededor del día 16 del inicio de los síntomas; se evidenció una mejoría de los síntomas (fiebre, tos, disnea, dolor torácico) y parámetros respiratorios (saturación de oxígeno) a los tres días del tratamiento; así mismo, aumento del recuento de linfocitos, disminución de la proteína $\mathrm{C}$ reactiva (PCR), mejoría de lesiones radiológicas dentro de la primera semana, carga viral no detectable en siete pacientes y aumento del título de anticuerpos neutralizantes de 1:640 en cinco pacientes. No se observaron eventos adversos severos después de las transfusiones.

Zeng et al. realizaron un estudio retrospectivo para evaluar la eficacia de la TPC (grupo de plasma) comparado con pacientes que solo recibieron tratamiento estándar (grupo control) hospitalizados en la unidad de cuidados intensivos (UCI) ${ }^{(28)}$. Se usó plasma de pacientes jóvenes recuperados de la COVID-19 y con anticuerpos IgM e IgG antiSARS-CoV-2 negativos. Se incluyeron seis pacientes en el grupo de plasma y 15 en el grupo control. Se administró solo una dosis de PC (300 mL) 21 después del diagnóstico. La administración tardía podría explicar porque solo un paciente sobrevivió en el grupo de plasma a pesar de no detectarse carga viral en los pacientes.

Olivares-Gazca et al. realizaron un estudio piloto prospectivo, de un solo brazo y cuasiexperimental en México para evaluar la eficacia de la TPC en diez pacientes con la COVID-19 hospitalizados en la UCI ${ }^{(29)}$. Los donantes del plasma fueron negativos al SARS-CoV-2 en al menos dos pruebas consecutivas de RCP; el volumen medio del plasma obtenido de los donantes fue de $700 \mathrm{~mL}$. Durante un periodo de ocho días, se evidenció una disminución significativa de la escala SOFA, de la temperatura corporal y de los niveles de ferritina, así como un aumento de la proporción $\mathrm{PaO}_{2} /$ $\mathrm{FiO}_{2}$. Las lesiones pulmonares mejoraron en siete (usando radiografía de tórax) y en seis pacientes (usando tomografía de tórax). Tres de los cinco pacientes que se encontraban con ventilación mecánica pudieron extubarse, nueve fueron trasladados a pisos de hospitales convencionales y seis recibieron el alta; sin embargo, dos pacientes murieron. La supervivencia global luego de 24 días de la transfusión fue de $77 \%$.

Erkurt et al. trataron con TPC a 26 pacientes con la COVID-19 grave hospitalizados en la UCI en Turquía ${ }^{(30)}$. Los donantes de plasma fueron pacientes con por lo menos 14 días de 
Tabla 2. Estudios que evaluaron el uso de plasma convaleciente en pacientes con COVID-19.

\begin{tabular}{|c|c|c|c|c|c|c|c|}
\hline Autor - país & $\begin{array}{l}\text { Tipo de } \\
\text { estudio }\end{array}$ & Número de pacientes & $\begin{array}{l}\text { Título de anticuerpos en } \\
\text { donantes }\end{array}$ & Dosis de PC & Resultados & Carga viral & $\begin{array}{l}\text { Eventos adversos y } \\
\text { complicaciones }\end{array}$ \\
\hline $\begin{array}{l}\text { Shen et al. } \\
\text { China }\end{array}$ & Serie de casos & 5 & $\begin{array}{l}\text { ELISA IgG } \\
>1: 1000 \\
\text { TAN }>1: 40\end{array}$ & $\begin{array}{l}400 \mathrm{~mL} \text { en dos } \\
\text { dosis el mismo } \\
\text { día }\end{array}$ & $\begin{array}{l}\text { Normalización de la temperatura a los } 3 \\
\text { días en } 4 \text { pacientes. } \\
\text { Disminución de la escala SOFA, aumen- } \\
\text { to de } \mathrm{PaO}_{2} / \mathrm{FiO} \mathrm{O}_{2} \text { dentro de los } 12 \text { días. } \\
\text { Aumento de anticuerpos neutralizantes } \\
\text { (de rango } 40-60 \text { a } 80-320 \text { al día } 7 \text { ). }\end{array}$ & $\begin{array}{l}\text { Disminución e indetecta- } \\
\text { ble dentro de los } 12 \text { días } \\
\text { después del tratamiento. }\end{array}$ & $\begin{array}{l}\text { No se reportaron eventos } \\
\text { adversos ni complica- } \\
\text { ciones. }\end{array}$ \\
\hline $\begin{array}{l}\text { Ye et al. } \\
\text { China }\end{array}$ & Serie de casos & 6 & No se reportó & $\begin{array}{l}200 \text { mL en } 1 \text { a } \\
3 \text { dosis }\end{array}$ & $\begin{array}{l}\text { Solo } 5 \text { pacientes presentaron lesiones } \\
\text { radiológicas } \\
\text { Mejoría clínica (a las } 24 \text { horas) y radio- } \\
\text { lógica (entre } 3 \text { días y } 2 \text { semanas). } \\
\text { Solo se reportó incremento de anticuer- } \\
\text { pos IgG e IgM en un paciente ( } 2 \text { veces). }\end{array}$ & $\begin{array}{l}\text { Disminución e indetectable } \\
\text { a los } 8 \text { días ( } 1 \text { paciente) } \\
3 \text { pacientes fueron negativos } \\
\text { antes del tratamiento. } \\
\text { No se reportó en } 2 \text { pa- } \\
\text { cientes. }\end{array}$ & $\begin{array}{l}\text { No se reportaron eventos } \\
\text { adversos ni complica- } \\
\text { ciones. }\end{array}$ \\
\hline $\begin{array}{l}\text { Duan et al. } \\
\text { China }\end{array}$ & Serie de casos & 10 & TAN $>1: 160$ & $\begin{array}{l}200 \text { mL en una } \\
\text { dosis el mismo } \\
\text { día }\end{array}$ & $\begin{array}{c}\text { Mejoría de sintomatología dentro de } \\
\text { los } 3 \text { días. } \\
\text { Aumento de saturación de oxígeno } \\
\text { dentro de los } 3 \text { días } \\
\text { Mejoría de lesiones radiológicas dentro } \\
\text { de la primera semana de tratamiento } \\
\text { Rápido aumento de anticuerpos neutra- } \\
\text { lizantes a 1:64 (en 5 pacientes). } \\
\text { Anticuerpos neutralizantes perma- } \\
\text { necieron altos a títulos de 1:640 (en } 4 \\
\text { pacientes). }\end{array}$ & $\begin{array}{l}\text { Disminución e indetectable } \\
\text { en la primera semana } \\
\text { después del tratamiento. }\end{array}$ & $\begin{array}{l}1 \text { paciente presentó un } \\
\text { exantema facial evanes- } \\
\quad \text { cente. } \\
\text { No se reportaron even- } \\
\text { tos adversos severos ni } \\
\text { complicaciones. }\end{array}$ \\
\hline $\begin{array}{l}\text { Zeng et al. } \\
\text { China }\end{array}$ & $\begin{array}{l}\text { Estudio retros- } \\
\text { pectivo }\end{array}$ & 21 & No se reportó & $\begin{array}{l}\text { Media de } 300 \mathrm{~mL} \\
\text { en } 1 \text { a } 2 \text { dosis }\end{array}$ & $\begin{array}{c}2 \text { grupos: } 6 \text { pacientes en grupo plasma, } \\
15 \text { pacientes en grupo control. } \\
\text { Solo un paciente sobrevivió en cada } \\
\text { grupo. } \\
\text { Mayor periodo de supervivencia en el } \\
\text { grupo plasma. }\end{array}$ & $\begin{array}{l}\text { Disminución e indetectable } \\
\text { en el grupo plasma, no se } \\
\text { reportó tiempo. }\end{array}$ & $\begin{array}{l}\text { No se reportaron eventos } \\
\text { adversos ni complica- } \\
\text { ciones. }\end{array}$ \\
\hline $\begin{array}{l}\text { Olivares-Gaz- } \\
\text { ca et al. } \\
\text { México }\end{array}$ & $\begin{array}{l}\text { Estudio piloto, } \\
\text { prospectivo, } \\
\text { cuasi experi- } \\
\text { mental }\end{array}$ & 10 & No se reportó & $\begin{array}{l}200 \mathrm{~mL} \text { (no se } \\
\text { reportó dosis) }\end{array}$ & $\begin{array}{l}\text { Evaluación } 8 \text { días después evidenció } \\
\text { una disminución significativa de la } \\
\text { escala SOFA, temperatura, y ferritina, un } \\
\text { aumento significativo de } \mathrm{PaO} 2 / \mathrm{FiO} 2 \\
\text { Mejoría radiológica de las lesiones } \\
\text { pulmonares } \\
\text { Supervivencia a los } 24 \text { días: } 77 \%\end{array}$ & No se reportó & $\begin{array}{l}\text { No se reportaron eventos } \\
\text { adversos ni complica- } \\
\text { ciones. }\end{array}$ \\
\hline $\begin{array}{l}\text { Erkut et al. } \\
\text { Turquía }\end{array}$ & $\begin{array}{l}\text { Estudio } \\
\text { prospectivo }\end{array}$ & 26 & No se reportó & $\begin{array}{l}200 \mathrm{~mL} \text { en una } \\
\text { dosis el mismo } \\
\text { día. }\end{array}$ & $\begin{array}{l}\text { No se reportó diferencia significativa } \\
\text { en el número de leucocitos, neutrófilos, } \\
\text { linfocitos, PCR, ferritina, saturación } \\
\text { de oxígeno } 1 \text { semana después del } \\
\text { tratamiento. } \\
6 \text { pacientes fallecieron: mayor edad y } \\
\text { linfopenia grave que los que sobrevi- } \\
\text { vieron. }\end{array}$ & No se reportó & $\begin{array}{l}\text { No se reportaron eventos } \\
\text { adversos ni complica- } \\
\text { ciones. }\end{array}$ \\
\hline $\begin{array}{l}\text { Perotti et al. } \\
\text { Italia }\end{array}$ & $\begin{array}{l}\text { Estudio } \\
\text { prospectivo }\end{array}$ & 46 & $\begin{array}{c}\text { TAN en primera infu- } \\
\text { sión: 1:160 o 1:320 ( } 85 \% \\
\text { pacientes), } 1: 320 \text { ( } 12 \% \\
\text { pacientes) y 1:80 en } 1 \\
\text { paciente } \\
\text { TAN en segunda infu- } \\
\text { sión: 1:80 (2 pacientes), } \\
\text { 1:160 (11 pacientes), } \\
\text { 1:320 (7 pacientes) y } \\
\text { 1:640 en 1 paciente } \\
\text { TAN en tercera infusión: } \\
\text { 1:320 en } 1 \text { paciente }\end{array}$ & $\begin{array}{l}24 \text { recibieron } 1 \\
\text { unidad de } P C, 21 \\
\text { recibieron } 2 \text { uni- } \\
\text { dades y } 1 \text { recibió } \\
\quad 3 \text { unidades }\end{array}$ & $\begin{array}{c}\text { Mortalidad: } 6,5 \% \text { ( } 3 \text { pacientes) } \\
\text { Aumento de PaO2/FiO2, mejoría radio- } \\
\text { lógica y disminución de ferritina, PCR y } \\
\text { lactato deshidrogenasa a los } 7 \text { días. } \\
29 \text { pacientes dejaron de usar soporte } \\
\text { ventilatorio a los } 2 \text { días. }\end{array}$ & $\begin{array}{c}\text { Disminución e indetectable } \\
\text { a los } 7 \text { días. }\end{array}$ & $\begin{array}{l}5 \text { eventos adversos severos } \\
\text { en } 4 \text { pacientes: fiebre } \\
\text { durante la transfusión, } \\
\text { embolismo pulmonar } \\
\text { subsegmentario, anafilaxia, } \\
\text { TRALI y urticaria (evento } \\
\text { probable, excluido, posible, } \\
\text { posible y probable, respec- } \\
\text { tivamente). } 1 \text { transfusión } \\
\text { detenida. }\end{array}$ \\
\hline $\begin{array}{l}\text { Abolghasemi } \\
\text { et al. - Irán }\end{array}$ & $\begin{array}{l}\text { Casos y } \\
\text { controles }\end{array}$ & $\begin{array}{l}189 \text { pacientes } \\
\text { (grupo plasma: } 115 \text {, } \\
\text { grupo control: } 74 \text { ) }\end{array}$ & $\begin{array}{l}\text { ELISA IgG e IgM semi } \\
\text { cuantitativo }>1,1\end{array}$ & $\begin{array}{c}500 \mathrm{~mL} \text { en } 4 \\
\text { horas. Si no se } \\
\text { evidenciaba me- } \\
\text { joría clínica luego } \\
\text { de } 24 \text { horas, se } \\
\text { administraba una } \\
\text { dosis más. }\end{array}$ & $\begin{array}{l}\text { Mortalidad: } 14,8 \% \text { en grupo plasma vs. } \\
24,3 \% \text { en grupo control. } \\
28,1 \% \text { grupo plasma recibieron el alta } \leq \\
5 \text { días vs. } 8,9 \% \text { en grupo control. } \\
\text { Estadía hospitalaria: grupo plasma: } 9,54 \\
\text { días vs. } 12,88 \text { días en grupo control. } \\
7 \% \text { grupo plasma necesitaron intuba- } \\
\text { ción vs. } 20 \% \text { en grupo control. }\end{array}$ & No se reportó & $\begin{array}{l}1 \text { evento adverso leve: } \\
\text { fiebre leve transitoria y } \\
\text { escalofríos. } \\
\text { No se reportaron eventos } \\
\text { adversos ni complica- } \\
\text { ciones. }\end{array}$ \\
\hline $\begin{array}{l}\text { Joyner et al. } \\
\text { Estados } \\
\text { Unidos }\end{array}$ & Retrospectivo & $\begin{array}{l}5000 \text { pacientes que } \\
\text { recibieron PC }\end{array}$ & No se reportó & No se reportó & $\begin{array}{l}\text { Incidencia de eventos adversos en la } \\
\text { primera hora de transfusión }<1 \% \text {. } \\
\text { Tasa de mortalidad a los } 7 \text { días: } 14,9 \% \text {. }\end{array}$ & No se reportó & $\begin{array}{c}36 \text { eventos adversos seve- } \\
\text { ros: } 15 \text { muertes, } 7 \text { casos de } \\
\text { TACO, } 11 \text { casos de TRALI, } \\
3 \text { casos de reacciones } \\
\text { alérgicas. }\end{array}$ \\
\hline $\begin{array}{l}\text { Li et al. } \\
\text { China }\end{array}$ & Ensayo clínico & $\begin{array}{l}103 \text { pacientes: } 52 \text { en } \\
\text { grupo plasma }(23 \text { con } \\
\text { enfermedad grave, } \\
29 \text { con enfermedad } \\
\text { crítica), } \\
51 \text { en grupo control } \\
\text { (22 con enfermedad } \\
\text { grave, } 29 \text { con enfer- } \\
\text { medad crítica) }\end{array}$ & $\begin{array}{c}\text { TAN de 1:80 es equiva- } \\
\text { lente a un título de 1:1280 } \\
\text { de anticuerpos IgG espe- } \\
\text { cíficos contra el dominio } \\
\text { de unión al receptor de la } \\
\text { proteína Spike (medido } \\
\text { por ELISA) }\end{array}$ & $\begin{array}{l}4 \text { a } 13 \mathrm{~mL} / \mathrm{Kg} . \\
10 \mathrm{~mL} \text { en los } \\
\text { primeros } 15 \\
\text { minutos luego se } \\
\text { aumentó a } 100 \\
\text { mL por hora }\end{array}$ & $\begin{array}{l}\text { No diferencia significativa en tiempo de } \\
\text { mejoría clínica a los } 28 \text { días. } \\
\text { Pacientes con enfermedad grave presen- } \\
\text { taron mayor mejoría clínica a los } 28 \text { días } \\
\text { que los pacientes críticos. } \\
\text { No diferencia significativa en la morta- } \\
\text { lidad a los } 28 \text { días, en el tiempo desde la } \\
\text { aleatorización hasta la muerte o hasta el } \\
\text { alta hospitalaria. }\end{array}$ & $\begin{array}{c}\text { Porcentaje de negatividad } \\
\text { de carga viral a las } 24,48 \text { y } \\
72 \text { horas de la transfusión } \\
\text { fue mayor significativamen- } \\
\text { te en grupo plasma y en } \\
\text { pacientes con enfermedad } \\
\text { crítica. } \\
\text { El porcentaje de negativi- } \\
\text { dad fue mayor pacientes } \\
\text { con enfermedad grave } \\
\text { solo a las } 72 \text { horas de la } \\
\text { transfusión }\end{array}$ & $\begin{array}{c}2 \text { pacientes: } \\
1 \text { con enfermedad grave } \\
\text { (exantema y escalofríos } \\
\text { dentro de } 2 \text { horas de la } \\
\text { transfusión). } \\
1 \text { con enfermedad crítica } \\
\text { (cianosis y disnea dentro } \\
\text { de } 6 \text { horas de la trans- } \\
\text { fusión). }\end{array}$ \\
\hline
\end{tabular}

ELISA: Ensayo de inmunoabsorción ligado a enzima; PCR: proteína C reactiva; TAN: Título de anticuerpos neutralizantes; TRALI: lesión pulmonar aguda producida por transfusión; SOFA: Sequential Organ Failure Assessment; TACO: sobrecarga circulatoria por transfusión. 
recuperación de enfermedad leve o moderada y con pruebas negativas por RCP y por serología. Se recolectaron entre 500 a 600 $\mathrm{mL}$ de plasma. Se evidenciaron infiltrados neumónicos, usando tomografía, en todos los pacientes. No se evidenciaron diferencias significativas del nivel de leucocitos, neutrófilos, linfocitos, plaquetas, PCR, ferritina y saturación de oxígeno después de una semana de tratamiento. No se reportaron reacciones adversas severas. Seis pacientes que estaban en ventilación mecánica fallecieron, por otro lado, no se reportaron muertes en el grupo de pacientes sin ventilación mecánica lo que indicaría que el tratamiento es eficaz en estadios iniciales de la enfermedad.

Perotti et al. realizaron un estudio en tres centros médicos de Italia para evaluar la eficacia y seguridad de la TPC en pacientes con la COVID-19 moderada y grave ${ }^{(31)}$. Se incluyeron a 46 pacientes, 37 pacientes estuvieron con oxígeno suplementario (7 intubados), 36 presentaron infiltrados bilaterales multilobares al examen radiológico y más del $80 \%$ fueron tratados con antibióticos, hidroxicloroquina y anticoagulantes. La cantidad de transfusiones realizadas fue variable: 24 recibieron una unidad, 21 recibieron dos unidades $\mathrm{y}$ uno recibió tres unidades. Tres pacientes murieron dentro de los siete días (6,5\%), dos de ellos presentaron diabetes, hipertensión y cáncer, mientras que el tercero presento una proporción $\mathrm{PaO}_{2} / \mathrm{FiO}_{2}$ de 67. A los siete días de administrarse el plasma, se evidenció un aumento de la proporción $\mathrm{PaO}_{2} / \mathrm{FiO}_{2}$, desaparición de las lesiones pulmonares en $23 \%$ de los pacientes, disminución de los niveles de ferritina, PCR y lactato deshidrogenasa, y 29 pacientes no necesitaron oxígeno suplementario alrededor de dos días después de la TPC. Se reportaron cinco eventos adversos severos en cuatro pacientes: anafilaxia, lesión pulmonar aguda producida por transfusión (TRALI), urticaria, embolismo pulmonar subsegmental y fiebre.

Abolghasemi et al. realizaron un estudio de casos y controles en seis hospitales de Irán ${ }^{(32)}$. Se reclutaron 189 pacientes hospitalizados con la COVID-19 con menos de ocho días desde el inicio de síntomas y que no estuvieran intubados o en ventilación mecánica, con choque séptico o con insuficiencia hepática o renal. 115 pacientes recibieron PC (grupo de plasma) y 74 correspondieron al grupo control. Ambos grupos recibieron tratamiento estándar con antivirales (lopinavir/ritonavir), hidroxicloroquina $\mathrm{y}$ agentes antiinflamatorios. Se transfundieron $500 \mathrm{~mL}$ de PC a cada paciente, y si luego de 24 horas no presentaba mejoría, se le administró una segunda unidad. Solo se observó una reacción adversa leve correspondiente a fiebre leve transitoria y escalofríos. Se evidenció una menor mortalidad, aunque no significativa, en el grupo de plasma (14,8\% vs. $24,3 \%)$; sí fue significativa la evidencia de una mayor frecuencia de alta ( $\leq 5$ días de la TPC), un menor tiempo de hospitalización y una menor frecuencia de intubación $(28,1 \%$ vs. $8,9 \%$; $9,54 \pm$ 5,07 días vs. $12,88 \pm 7,19$ días; $7 \%$ vs. $20,3 \%$ ).

Joyner et al. analizaron 5000 TPC administradas a pacientes con enfermedad grave o crítica (4051 [89\%]), y pacientes catalogados de tener alto riesgo de progresión a esta- dio grave o crítico (949 [19\%]), entre el 3 de abril y el 11 de mayo de 2020, como parte del programa de acceso expandido para recolección y distribución de PC de pacientes recuperados de la COVID-19 en los Estados Unidos ${ }^{(33)}$. El objetivo fue evaluar la seguridad del PC durante y después de las transfusiones. Se encontraron 36 eventos adversos severos asociados a la transfusión ( $<1 \%$ de las transfusiones) dentro de las primeras cuatro horas. De estos eventos adversos, 15 fueron fallecimientos ( $0,3 \%$ de las transfusiones) siendo cuatro catalogados como relacionadas a la transfusión (tres posibles y uno probable), siete fueron sobrecarga circulatoria asociada a transfusión (TACO), 11 fueron TRALI y tres fueron reacciones alérgicas graves. La mortalidad luego de siete días de la TPC fue de 14,9\% (602 pacientes), sin embargo, este valor podría ser similar o menor a la tasa de letalidad en general en pacientes hospitalizados (entre 10\% y 20\%), siendo mayor en la UCI.

Posteriormente, se publicó una actualización de este estudio con 20000 pacientes ${ }^{(34)}$. Aunque el estudio aún no está indexado en PubMed, nos parece importante mencionar que la incidencia de eventos adversos severos asociados a transfusión fue baja (89 casos $[<1 \%]$ ), la mortalidad a los siete días de la TPC fue de $8,6 \%$, siendo mayor en pacientes admitidos en la UCI vs. no admitidos (10,5\% vs. $6 \%$ ), en pacientes con ventilación mecánica vs. sin ventilación mecánica (12,1\% vs. $6,2 \%)$ y en pacientes con choque séptico o falla multiorgánica vs. sin falla orgánica ( $14 \%$ vs. $7,6 \%$ ). Los autores concluyen que el tratamiento es seguro y reduce la mortalidad en especial si la administración es en etapas iniciales de la enfermedad.

El único ensayo clínico aleatorizado que evaluó el efecto de la TPC en pacientes con la COVID-19 se realizó en ocho centros médicos en China, entre el 14 de febrero y el 28 de abril ${ }^{(35)}$. Se incluyeron un total de 103 pacientes con enfermedad grave ( $\geq 30$ respiraciones/minuto, saturación de oxígeno $\leq 93 \%$ o proporción $\mathrm{PaO}_{2} / \mathrm{FiO}_{2} \leq 300$ ) y crítica (uso de ventilación mecánica por insuficiencia respiratoria, choque u otra insuficiencia orgánica que necesite de monitoreo en la UCI). Los pacientes fueron divididos en dos grupos: 52 pacientes que recibieron tratamiento estándar y TPC (grupo plasma, 23 con enfermedad gravey 29 con enfermedad crítica) y un grupo control de 51 pacientes que solo recibieron tratamiento estándar (22 con enfermedad grave y 29 con enfermedad crítica). No se evidenció una disminución significativa en el tiempo de mejoría clínica 28 días después de la TPC (51,9\% en grupo plasma vs. $43,1 \%$ en grupo control; diferencia: 8,8\%, IC95\%: -10,4\%-28\%; hazard ratio (HR): 1,4; IC95\%: 0,79-2,49; $\mathrm{p}=0,260)$, en la mortalidad al día $28(15,7 \%$ en grupo plasma vs. $24 \%$ en grupo control; OR: 0,65, IC95\%: $0,29-1,46 ; p=0,300)$ y en el tiempo desde la aleatorización hasta el alta o muerte, mientras que el porcentaje de resultados negativos por RCP a las 24, 48 y 72 horas fueron significativamente mayores en el grupo de plasma. Adicionalmente, se reportaron dos eventos adversos postransfusión; escalofríos y exantema dentro de las dos horas en un paciente con enfermedad grave, disnea grave y cianosis dentro de las seis horas en un paciente con enfermedad crítica (los eventos fueron catalogados como 
definitivo y posiblemente asociado a transfusión; respectivamente).

Los autores concluyeron que el tratamiento con TPC no tiene beneficio en el tiempo de mejoría clínica dentro de los 28 días de la transfusión, sin embargo, la mejoría fue mayor en pacientes con enfermedad grave ( $91,3 \%$ vs. $68,2 \%$; HR: 2,15 , IC95\%: 1,07-4,32; $\mathrm{p}=0,030)$ que con enfermedad crítica $(20,7 \%$ vs. $24,1 \%$; HR: 0,88 , IC95\%: 0,3-2,63; $\mathrm{p}=0,830$ ), sugiriendo que su uso en etapas iniciales de la enfermedad tendría un mayor beneficio. El estudio cuenta con varias limitaciones como; un tamaño de muestra pequeño debido a la detención temprana del estudio, ya que no se reportaron nuevos casos después del 24 de marzo, ser un estudio abierto, uso de tratamiento estándar no protocolizado y un corto periodo de seguimiento.

Finalmente, se han realizado tres revisiones sistemáticas del uso de la TPC en pacientes con COVID-19. Sun et al. incluyeron 40 estudios que evaluaron el efecto de la TPC en pacientes con COVID-19 e infecciones causadas por otros coronavirus, gripe y Ébola, aunque estos presentaron alta heterogeneidad, baja calidad y un alto sesgo ${ }^{(36)}$. Se incluyeron 15 estudios para el metaanálisis (solo uno relacionado a la COVID-19), y se reportó disminución de la tasa de letalidad (OR: 0,32, IC95\%: 0,19-0,52), una disminución de la carga viral, un aumento de anticuerpos neutralizantes, una menor estadía hospitalaria y una ausencia de efectos adversos severos.

Rajendran et al. incluyeron cinco estudios publicados hasta abril de $2020^{(37)}$. Los estudios reportaron reducción significativa de la carga viral, aumento de los niveles de anticuerpos neutralizantes, mejoría de los síntomas, disminución de la mortalidad y ausencia de efectos adversos severos después de la TPC, sin embargo, los estudios presentaron limitaciones como sesgo moderado a alto, pobre desarrollo metodológico para la selección de los participantes (reporte de casos), dosaje de la TPC y duración de la terapia, por lo que, debido a la heterogeneidad de los estudios, no se pudo realizar un metaanálisis.

Piechotta et al. incluyeron 20 estudios publicados hasta el 4 de junio (un ensayo clínico, tres estudios controlados no aleatorizados y 16 estudios no controlados no aleatorizados), sin embargo, los estudios contaban con alto sesgo debido al diseño del estudio, tipo de pacientes y tratamientos usados ${ }^{(38)}$. Para el análisis de eficacia solo se incluyeron un ensayo clínico y tres estudios controlados no aleatorizados, donde no hubo evidencia suficiente para determinar el efecto de la TPC en el riesgo de muerte por cualquier causa hasta el día del alta, prolongación del tiempo hasta la muerte, o mejoría de síntomas clínicos (medido como necesidad de soporte ventilatorio). Por otro lado, se evaluó la seguridad, inclusive de los 20 estudios, solo 14 reportaron eventos adversos, como muerte, reacciones alérgicas o complicaciones respiratorias (TRALI), sin embargo, los resultados no presentan suficiente solidez para determinar si la TPC aumenta el número de eventos adversos.

Actualmente, se vienen conduciendo ensayos clínicos en diversas partes del mundo (95 hasta la fecha) ${ }^{(39)} \mathrm{y}$ tres en nuestro país ${ }^{(40)}$, que darán mayor solidez a la evidencia descrita previamente.

\section{SEGURIDAD DE LAS TRANSFUSIONES DE PLASMA CONVALECIENTE}

Como se resume en las secciones anteriores, los estudios que evaluaron la TPC en infecciones por coronavirus han reportado una baja frecuencia de eventos adversos. Sin embargo, existe el riesgo de que los pacientes presenten amplificación o potenciación dependiente de anticuerpos, fenómeno que ocurre cuando los anticuerpos facilitan la entrada del virus en las células huésped y aumentan la infección viral en estas, provocando un empeoramiento y exacerbación de la enfermedad al realizar la TPC ${ }^{(41)}$. Existe evidencia de este fenómeno en animales infectados por otros coronavirus, sin embargo, se desconocen los signos y síntomas específicos de $\mathrm{ADE}$ (antibody-dependent enhancement) en humanos con infección por coronavirus ${ }^{(41)}$. Se postula que podría estar asociado con un deterioro clínico después de la TPC y que se manifestaría durante la etapa más temprana de la enfermedad, sin embargo, no hay reportes de este fenómeno en pacientes con la COVID-19, por lo que es necesario una vigilancia continua de estos pacientes ${ }^{(33,42)}$.

\section{CONCLUSIONES}

El plasma convaleciente se ha usado para fines terapéuticos por más de un siglo, los anticuerpos que contiene tienen un efecto antiviral, así como actividad antinflamatoria no específica. Es muy probable que su mayor beneficio resulte mientras más temprano se administre durante el curso de la enfermedad dada la mayor carga viral durante los primeros días de la infección. La seguridad del plasma convaleciente se ha demostrado en otras infecciones, así como, en la infección por SARS-CoV-2 en recientes estudios. Sobre su efectividad en infección por SARS-CoV-2 podemos decir que la evidencia encontrada consiste en estudios principalmente observacionales. Queda aún pendiente en demostrar su efectividad en ensayos clínicos bien diseñados cuyos resultados esperamos aparezcan pronto dado el creciente número de ensayos clínicos que están en curso.

Contribuciones de autoría: CAG, CTD y MAA concibieron y diseñaron el trabajo. CAG, CTD, OAB y LSR adquirieron los datos y los analizaron. Todos los autores participaron en la redacción del manuscrito, proporcionaron comentarios críticos y aprobaron la versión final.

Financiamiento: Autofinanciado.

Conflictos de interés: Los autores declaran que no existe conflicto de intereses en relación con esta publicación. 


\section{REFERENCIAS BIBLIOGRÁFICAS}

1. World Health Organization. Coronavirus disease (COVID-2019) situation report - 203 [Internet]. Ginebra: WHO; 2020 [citado el 10 de agosto de 2020]. Disponible en: https://www.who.int/emergencies/diseases/ novel-coronavirus-2019/situation-reports.

2. Ministerio de Salud. Sala situacional COVID-19 [Internet]. Lima: Estado Peruano; 2020 [citado el 10 de agosto de 2020]. Disponible en: https:// covid19.minsa.gob.pe/sala_situacional.asp.

3. Casadevall A, Pirofski LA. The convalescent sera option for containing COVID-19. J Clin Invest. 2020;130(4):1545-48. doi: 10.1172/JCI138003.

4. Simon J. Emil Behring's medical culture: from disinfection to serotherapy. Med Hist. 2007;51(2):201-18. doi: 10.1017/s0025727300001198.

5. Serrano-Barrera OR, Bello-Rodríguez MM. Plasma humano de convalecientes, ahora un tratamiento para la COVID-19, tuvo su origen en Cuba. Rev Electron Zoilo. 2020;45(4).

6. Luke TC, Kilbane EM, Jackson JL, Hoffman SL. Meta-analysis: convalescent blood products for Spanish influenza pneumonia: a future H5N1 treatment?. Ann Intern Med. 2006;145(8):599-609. doi: 10.7326/00034819-145-8-200610170-00139.

7. Maiztegui JI, Fernandez NJ, de Damilano AJ. Efficacy of immune plasma in treatment of Argentine haemorrhagic fever and association between treatment and a late neurological syndrome. Lancet. 1979;2(8154):1216-7. doi: 10.1016/s0140-6736(79)92335-3.

8. Casadevall A. Passive antibody administration (immediate immunity) as a specific defense against biological weapons. Emerg Infect Dis. 2002;8(8):833-41. doi: 10.3201/eid0808.010516.

9. Luke TC, Casadevall A, Watowich SJ, Hoffman SL, Beigel JH, Burgess TH. Hark back: passive immunotherapy for influenza and other serious infections. Crit Care Med. 2010;38(4 Suppl):e66-73. doi: 10.1097/CCM.0b013e3181d44cle.

10. Winkler AM, Koepsell SA. The use of convalescent plasma to treat emerging infectious diseases: focus on Ebola virus disease. Curr Opin Hematol. 2015;22(6):521-6. doi: 10.1097/MOH.0000000000000191.

11. World Health Organization. Blood Regulators Network (BRN) - Position paper on use of convalescent plasma, serum or immune globulin concentrates as an element in response to an emerging virus [Internet]. Ginebra: WHO; 2017 [citado el 9 de agosto de 2020]. Disponible en: https://www.who.int/ bloodproducts/brn/2017_BRN_PositionPaper_ConvalescentPlasma.pdf.

12. World Health Organization. Use of convalescent whole blood or plasma collected from patients recovered from Ebola virus disease for transfusion, as an empirical treatment during outbreaks - interim guidance for national health authorities and blood transfusion services [Internet]. Ginebra: WHO; 2014 [citado el 9 de agosto de 2020]. Disponible en: http:// www.euro.who.int/_data/assets/pdf_file/0011/268787/Use-of-Convalescent-Whole-Blood-or-Plasma-Collected-from-Patients-Recovered-from-Ebola-Virus-Disease-for-Transfusion,-as-an-Empirical-Treatment-during-Outbreaks-Eng.pdf.

13. Tiberghien P, de Lambalerie X, Morel P, Gallian P, Lacombe K, Yazdanpanah Y. Collecting and evaluating convalescent plasma for COVID-19 treatment: why and how. Vox Sang. 2020. doi: 10.1111/vox.12926.

14. Casadevall A, Pirofski LA. Antibody-mediated regulation of cellular immunity and the inflammatory response. Trends Immunol. 2003;24(9):4748. doi: 10.1016/s1471-4906(03)00228-x.

15. Rojas M, Rodríguez Y, Monsalve DM, Acosta-Ampudia Y, Camacho B, Gallo JE, et al. Convalescent plasma in Covid-19: Possible mechanisms of action. Autoimmun Rev. 2020;19(7):102554. doi: 10.1016/j. autrev.2020.102554

16. Hogarth PM. Fc receptors are major mediators of antibody based inflammation in autoimmunity. Curr Opin Immunol. 2002;14(6):798-802. doi: 10.1016/s0952-7915(02)00409-0.

17. Robbins JB, Schneerson R, Szu SC. Perspective: hypothesis: serum IgG antibody is sufficient to confer protection against infectious diseases by inactivating the inoculum. J Infect Dis. 1995;171(6):1387-98. doi: 10.1093/ infdis/171.6.1387.
18. Marano G, Vaglio S, Pupella S, Facco G, Catalano L, Liumbruno GM, et al. Convalescent plasma: new evidence for an old therapeutic tool?. Blood Transfus. 2016;14(2):152-7. doi: 10.2450/2015.0131-15.

19. Dodd RY. Emerging pathogens and their implications for the blood supply and transfusion transmitted infections. Br J Haematol. 2012;159(2):13542. doi: 10.1111/bjh.12031.

20. Cheng Y, Wong R, Soo YO, Wong WS, Lee CK, Ng MH, et al. Use of convalescent plasma therapy in SARS patients in Hong Kong. Eur J Clin Microbiol Infect Dis. 2005;24(1):44-6. doi: 10.1007/s10096-004-1271-9.

21. Soo YO, Cheng Y, Wong R, Hui DS, Lee CK, Tsang KK, et al. Retrospective comparison of convalescent plasma with continuing high-dose methylprednisolone treatment in SARS patients. Clin Microbiol Infect. 2004;10(7):676-8. doi: 10.1111/j.1469-0691.2004.00956.x.

22. Yeh KM, Chiueh TS, Siu LK, Lin JC, Chan PK, Peng MY, et al. Experience of using convalescent plasma for severe acute respiratory syndrome among healthcare workers in a Taiwan hospital. J Antimicrob Chemother. 2005;56(5):919-22. doi: 10.1093/jac/dki346.

23. Mair-Jenkins J, Saavedra-Campos M, Baillie JK, Cleary P, Khaw FM, Lim WS, et al. The effectiveness of convalescent plasma and hyperimmune immunoglobulin for the treatment of severe acute respiratory infections of viral etiology: a systematic review and exploratory meta-analysis. J Infect Dis. 2015;211(1):80-90. doi: 10.1093/infdis/jiu396.

24. Ko JH, Seok H, Cho SY, Ha YE, Baek JY, Kim SH, et al. Challenges of convalescent plasma infusion therapy in Middle East respiratory coronavirus infection: a single centre experience. Antivir Ther. 2018;23(7):617-22. doi: 10.3851/IMP3243.

25. Shen C, Wang Z, Zhao F, Yang Y, Li J, Yuan J, et al. Treatment of 5 critically ill patients with COVID-19 with convalescent plasma. JAMA. 2020;323(16):1582-9. doi: 10.1001/jama.2020.4783.

26. Ye M, Fu D, Ren Y, Wang F, Wang D, Zhang F, et al. Treatment with convalescent plasma for COVID-19 patients in Wuhan, China. J Med Virol. 2020;1-12. doi: 10.1002/jmv.25882.

27. Duan K, Liu B, Li C, Zhang H, Yu T, Qu J, et al. Effectiveness of convalescent plasma therapy in severe COVID-19 patients. Proc Natl Acad Sci U S A. 2020;117(17):9490-6. doi: 10.1073/pnas.2004168117.

28. Zeng QL, Yu ZJ, Gou JJ, Li GM, Ma SH, Zhang GF, et al. Effect of convalescent plasma therapy on viral shedding and survival in COVID-19 Patients. J Infect Dis. 2020;222(1):38-43. doi: 10.1093/infdis/jiaa228.

29. Olivares-Gazca JC, Priesca-Marín JM, Ojeda-Laguna M, Garces-Eisele J, Soto-Olvera S, Palacios-Alonso A, et al. Infusion of convalescent plasma is associated with clinical improvement in critically ill patients with COVID-19: A pilot study. Rev Invest Clin. 2020;72(3):159-64. doi: 10.24875/RIC.20000237.

30. Erkurt MA, Sarici A, Berber İ, Kuku İ, Kaya E, Özgül M. Life-saving effect of convalescent plasma treatment in covid-19 disease: Clinical trial from eastern Anatolia. Transfus Apher Sci. 2020;102867. doi: 10.1016/j. transci.2020.102867.

31. Perotti C, Baldanti F, Bruno R, Del Fante C, Seminari E, Casari S, et al. Mortality reduction in 46 severe Covid-19 patients treated with hyperimmune plasma. A proof of concept single arm multicenter trial. Haematologica. 2020. doi: 10.3324/haematol.2020.261784.

32. Abolghasemi H, Eshghi P, Cheraghali AM, Fooladi AAI, Moghaddam FB, Imanizadeh S, et al. Clinical efficacy of convalescent plasma for treatment of COVID-19 infections: Results of a multicenter clinical study. Transfus Apher Sci. 2020;102875. doi: 10.1016/j.transci.2020.102875.

33. Joyner MJ, Wright RS, Fairweather D, Senefeld JW, Bruno KA, Klassen SA, et al. Early safety indicators of COVID-19 convalescent plasma in 5,000 patients. J Clin Invest. 2020;140200. doi: 10.1172/JCI140200.

34. Joyner MJ, Bruno KA, Klassen SA, Kunze KL, Johnson PW, Lesser ER, et al. Safety update: COVID-19 convalescent plasma in 20,000 hospitalized patients. Mayo Clin Proc. 2020. doi: 10.1016/j.mayocp.2020.06.028.

35. Li L, Zhang W, Hu Y, Tong X, Zheng S, Yang J, et al. Effect of convalescent plasma therapy on time to clinical improvement in patients with severe 
and life-threatening COVID-19: A randomized clinical trial. JAMA. 2020;324(5):1-11. doi: 10.1001/jama.2020.10044.

36. Sun $\mathrm{M}, \mathrm{Xu} \mathrm{Y}, \mathrm{He} \mathrm{H}$, Zhang $\mathrm{L}$, Wang $\mathrm{X}$, Qiu Q, et al. A potentially effective treatment for COVID-19: A systematic review and meta-analysis of convalescent plasma therapy in treating severe infectious disease. Int J Infect Dis. 2020;98:334-46. doi: 10.1016/j.ijid.2020.06.107.

37. Rajendran K, Narayanasamy K, Rangarajan J, Rathinam J, Natarajan M, Ramachandran A. Convalescent plasma transfusion for the treatment of COVID-19: Systematic review. J Med Virol. 2020:1-9. doi: 10.1002/ jmv.25961.

38. Piechotta V, Chai KL, Valk SJ, Doree C, Monsef I, Wood EM, et al. Convalescent plasma or hyperimmune immunoglobulin for people with COVID-19: a living systematic review. Cochrane Database Syst Rev. 2020;7(7):CD013600. doi: 10.1002/14651858.CD013600.pub2.
39. National Institute of Health [Internet]. Bethesda: NIH; 2020 [citado el 10 de agosto de 2020]. Disponible en: https://clinicaltrials.gov/ct2/ results? cond $=$ convalescent + plasma $+\&$ term $=$ covid $-19 \&$ cntry $=\&$ sta te $=\&$ city $=\&$ dist $=$.

40. Instituto Nacional de Salud. Registro Peruano de Ensayos Clínicos; [Internet]. Lima: INS; 2020 [citado el 10 de agosto de 2020]. Disponible en: https://ensayosclinicos-repec.ins.gob.pe/acerca-del-repec/busqueda-de-ensayos-clinicos.

41. Wan Y, Shang J, Sun S, Tai W, Chen J, Geng Q, et al. Molecular Mechanism for Antibody-Dependent Enhancement of Coronavirus Entry. J Virol. 2020;94(5):e02015-19. doi: 10.1128/JVI.02015-19.

42. Fleming AB, Raabe V. Current studies of convalescent plasma therapy for COVID-19 may underestimate risk of antibody-dependent enhancement. J Clin Virol. 2020;127:104388. doi: 10.1016/j.jcv.2020.104388. 